\title{
CALCIUM CONTACTS TO N-TYPE CRYSTALLINE SILICON SOLAR CELLS
}

Authors: Thomas G. Allen*, James Bullock, Peiting Zheng, Ben Vaughan, Matthew Barr, Yimao Wan, Christian Samundsett, Daniel Walter, Ali Javey and Andres Cuevas

Keywords: partial rear contacts, dopant-free contacts, calcium, work function, barrier height, contact resistance

ABSTRACT

$=$

Direct metallization of lightly doped n-type crystalline silicon (c-Si) is known to routinely produce non-Ohmic (rectifying) contact behavior. This has inhibited the development of n-type c-Si solar cells with partial rear contacts (PRC), an increasingly popular cell design for high performance p-type c-Si solar cells. In this contribution we demonstrate that low resistance Ohmic contact to n-type c-Si wafers can be achieved by incorporating a thin layer of the low work function metal calcium (

resistivities of $\rho_{\mathrm{c}} \sim 2 \mathrm{~m} \Omega \mathrm{cm}^{2}$ can be realised on undiffused n-type silicon wafers, thus enabling PRC cell designs on n-type silicon without the need for a phosphorus diffusion. Integrating the $\mathrm{Ca} / \mathrm{Al}$ stack into a partial rear contact solar cell architecture fabricated on a lightly doped $\left(N_{\mathrm{D}}=4.5 \times 10^{14} \mathrm{~cm}^{-3}\right)$ n-type wafer resulted in a device efficiency of $\eta=17.6 \%$ where the $\mathrm{Ca} / \mathrm{Al}$ contact comprised only $\sim 1.26 \%$ of the rear surface. We demonstrate an improvement in this cell structure to an efficiency of $\eta=20.3 \%$ by simply increasing the wafer doping by an order of magnitude to $N_{\mathrm{D}}=5.4 \times 10^{15} \mathrm{~cm}^{-3}$.

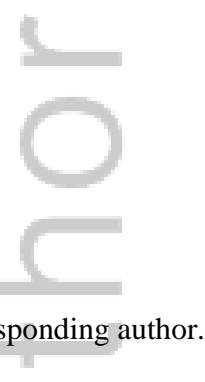

Email: thomas.allen@anu.edu.au

This is the author manuscript accepted for publication and has undergone full peer review but has not been through the copyediting, typesetting, pagination and proofreading process, which may lead to differences between this version and the Version of Record. Please cite this article as doi: $10.1002 /$ pip.2838 


\section{INTRODUCTION}

The formation of carrier selective contacts for both electrons and holes is critical to the functionality of any photovoltaic device. In crystalline silicon (c-Si) solar cells this is typically achieved by thermally diffusing or physically depositing acceptor and donor doped layers within the contact structure. This approach to contact formation can lead to slow and complex fabrication procedures, typically performed at high temperatures, and necessarily results in unwanted energy loss mechanisms like free carrier absorption [1] and Auger recombination [2]. Balancing the trade-off between the fundamental losses and fabrication processes is a complicated and often dynamic engineering challenge.

Progress has recently been made in overcoming these challenges by the development of dopant-free contact structures on crystalline silicon. Advances have been particularly striking at the hole contact, with the fabrication of high efficiency devices incorporating PEDOT:PSS [3] and sub-stoichiometric $\mathrm{MoO}_{\mathrm{x}}$ [4], [5] hole-selective contacts. The lower resistivity of the direct p-type c-Si / $\mathrm{MoO}_{\mathrm{x}}$ contact $\left(\rho_{\mathrm{c}} \sim 1 \mathrm{~m} \Omega \mathrm{cm}^{2}\right)$ [6] compared to other hole-selective materials has even made $\mathrm{MoO}_{\mathrm{x}}$ applicable to p-type cell architectures with partial rear contacts (PRC) [7]. The fabrication of dopant-free PRC solar cells on phosphorus doped n-type silicon, considered a more robust material for solar cell devices due to its relative insensitivity to common impurities like oxygen and iron, has, until recently, not been possible due to the technological challenges associated with contacting lowly doped n-type silicon.

Historically it is well known that direct metal contacts consistently exhibit non-Ohmic (rectifying) $I$ - $V$ behavior when applied to lowly doped n-type silicon for the range of metals commonly used to contact silicon solar cells. This is due to the Fermi level pinning phenomenon, whereby the Fermi level at the silicon surface is consistently held at values below the intrinsic Fermi level for metals like aluminium, copper, chromium and silver [8]. In practice, this means that larger energy barriers for electrons tend to form at the n-type $\mathrm{Si} /$ metal interface, while conversely, smaller energy barriers tend to form for holes at the p-type $\mathrm{Si} /$ metal interface. However, the work of Bullock et al., in which a thin layer of the work function modifier $\mathrm{LiF}$ was incorporated into a c-Si / $\mathrm{LiF} / \mathrm{Al}$ contact [9], demonstrates that by significantly lowering the metal work function, dopant free electron contacts are realisable on moderately doped n-type silicon wafers, leading to the first demonstration of an n-type PRC cell without the use of heavy doping [10].

Ideally though the direct metallization of a lowly doped silicon wafer would achieve selectivity of either electrons or holes by virtue of its work function. Herein we document our progress in overcoming the limitations of typical n-type silicon / metal contacts by utilizing calcium, a low work function (

photovoltaic devices [11]. We demonstrate low resistivity $\left(\rho_{\mathrm{c}} \sim 2 \mathrm{~m} \Omega \mathrm{cm}^{2}\right)$ Ohmic contact to moderately doped n-type silicon 
by a thermally evaporated $\mathrm{Ca} / \mathrm{Al}$ contact structure. We go on to apply the directly metallized $\mathrm{Ca} / \mathrm{Al}$ contact structure to $\mathrm{n}$ type partial rear contact (PRC) solar cells with contact fractions $f_{\mathrm{c}}=0.32 \%$ and $1.26 \%$. To highlight the efficacy of the Ca / Al contact we fabricated the cells on lightly phosphorus doped $\left(N_{\mathrm{D}}=4.5 \times 10^{14} \mathrm{~cm}^{-3}\right)$ n-type wafers, measuring a device efficiency of $\eta=17.6 \%$. Applying the same cell architecture to a $N_{\mathrm{D}}=5.4 \times 10^{15} \mathrm{~cm}^{-3}$ phosphorus doped wafer resulted in an increase in the efficiency to $\eta=20.3 \%$.

\section{CONTACT RESISTANCE}

Thin, $\sim 30 \mathrm{~nm}$, layers of calcium were thermally evaporated at low vacuum pressures (between $1 \times 10^{-7}$ and $1 \times 10^{-6}$ Torr) from a solid source in a glovebox-integrated metal evaporator. An initial $\sim 150 \mathrm{~nm}$ capping layer of $\mathrm{Al}$ was sequentially evaporated in the same chamber without breaking vacuum. A further $\sim 150 \mathrm{~nm}$ of $\mathrm{Al}$ was subsequently evaporated after breaking vacuum to thicken the capping layer.

Contact resistance measurements were performed using Cox and Strack [12] and transfer length method (TLM) [13] test structures. All contact resistance structures were fabricated using shadow masks to define the contact geometry. The rear contact of the Cox and Strack test structure was formed by evaporating $\mathrm{Al}(>500 \mathrm{~nm})$ on a phosphorus diffused $\mathrm{n}^{+}$surface in order to increase the sensitivity of the measurement. The contact resistivity was extracted from the $I$ - $V$ data obtained from a Keithley 2420 source meter.

Figure 1 shows the total measured resistance $R_{\text {total }}$ of the Cox and Strack structure as a function of the top contact diameter. The inset graph features a subset of the $I-V$ curves used to determine the data in the main figure for the $\mathrm{Ca} / \mathrm{Al}$ contact, as well as an $I-V$ curve of a direct $\mathrm{Al}$ contact to the same $1.2 \Omega \mathrm{cm}$ n-type wafer, demonstrating the typical rectifying behavior of Al contacts to undiffused n-type surfaces. Since the contact structure features front and rear side contacts and bulk transport through the whole wafer thickness, the sensitivity of the measurement is limited by contributions to $R_{\text {total }}$ by both the rear contact resistance and the bulk resistance (a function of wafer thickness and doping). To illustrate this, we have plotted the intrinsic spreading resistance in the figure, which assumes no resistive contribution from the front $\mathrm{Ca} / \mathrm{Al}$ or rear $\mathrm{n}^{+} / \mathrm{Al}$ contacts. From the $R_{\text {total }}$ measurements of Figure 1 we estimate the contact resistivity of the Ca / $\mathrm{Al}$ contact to be $\rho_{\mathrm{c}} \sim$ $2 \mathrm{~m} \Omega \mathrm{cm}^{2}$. Note, however, that many data points lie below the modelled value and are indistinguishable from the intrinsic resistance of the bulk wafer, indicating the contact resistivity extraction is within the sensitivity of the technique and, therefore, the extracted value represents an upper limit to $\rho_{\mathrm{c}}$. 
To investigate the stability of the contact resistance the same test structure was remeasured 14 months after the initial measurement, during which time the sample was stored unencapsulated in ambient conditions. The resulting change in the contact resistance is represented by the purple crosses in Figure 1. The data demonstrate that the contact resistivity has remained relatively stable over this period with any potential increase in the contact resistivity being within the error of the measurement.

Subsequent $\mathrm{Ca} / \mathrm{Al}$ evaporations were performed at higher pressures $\left(\sim 1 \times 10^{-6}\right.$ Torr $)$ than those of Figure 1 . The resulting contact resistance, as determined by the TLM test structures are plotted in Figure 2 as a function of wafer doping after subtracting the series resistance of the measurement setup, determined from a pad-to-pad resistance measurement. The results plotted in Figure 2 indicate a strong trend of increasing contact resistivity with decreasing wafer doping, which is similar to the results of Bullock et al. for the $\mathrm{LiF} / \mathrm{Al}$ contact structure [10]. This trend is consistent, for data at $N_{\mathrm{D}} \sim 5 \times 10^{15}$ $\mathrm{cm}^{-3}$, with a low barrier height forming at the $\mathrm{n}$-type $\mathrm{Si} / \mathrm{Ca}$ interface, determined by Crowell et al. to be $\sim 0.4 \mathrm{eV}$ for the $\mathrm{n}$ type Si / Ca contact [14]. Note that for a metal with such a low work function (Ca $\mathbf{\phi} \sim \mathbf{2 . 9} \mathbf{~ e V})$, Schottky-Mott theory would predict a negative barrier height, that is, an accumulation of electrons at the contact interface. Clearly Fermi-level pinning is still significant in this contact structure, though the work function of calcium is low enough in this instance to contain its effect on $\rho_{\mathrm{c}}$ to suitably low values.

Interestingly, Ohmic contact is maintained over the current density range investigated, even on the very lowly doped wafer $\left(N_{\mathrm{D}} \sim 4.3 \times 10^{13} \mathrm{~cm}^{-3} ; \rho \sim 100 \Omega \mathrm{cm}\right)$ though the value of the contact resistivity is extremely high - a result that is likely attributable to extraneous bulk resistance effects. The analyses of Berger [15] and Woelk et al. [16] indicate that the sensitivity of the transmission line model (a precursor to the transfer length method) can be limited by contributions to the total resistance by spreading resistance into the semiconductor bulk material, leading to an overestimation of $\rho_{\mathrm{c}}$ when the semiconductor sheet resistance is high and when the 'sheet' thickness departs significantly from the 1D assumption (i.e. for a thick semiconductor layer). They restrict the applicability of the TLM technique to structures in which the ratio of vertical resistances of the interface and semiconductor layer per unit area $(\eta)$, defined as $\eta=\rho_{\mathrm{c}} /\left(\rho_{\mathrm{s}} \cdot h\right)$, are much greater than 0.19 , where $\rho_{\mathrm{s}}$ is the semiconductor resistivity and $h$ the thickness. For values of $\eta$ lower than this, the spreading resistance dominates over the contact resistance. For values of $0.19<\eta<2$ Berger introduced the extended transmission line model (ETLM) model to account for errors associated with bulk spreading resistance contributions. Applying the ETLM correction of Berger to the data at $N_{\mathrm{D}}=5.3 \times 10^{15} \mathrm{~cm}^{-3}(\eta \sim 0.3)$ reduces the extracted apparent contact resistivity from $5.9 \mathrm{~m} \Omega \mathrm{cm}^{2}$ to 2.1 $\mathrm{m} \Omega \mathrm{cm}^{2}$, a value in agreement with the value extracted from the Cox and Strack data of Figure 1. For the data of Figure 2 at 
lower dopant densities the value of $\eta$ falls below the range of applicability of both the TLM technique and Berger's correction (i.e., $\eta<0.19$ ) and so the apparent increase in $\rho_{\mathrm{c}}$ may be an artefact of the uncorrected TLM measurement.

Recently, Eidelloth and Brendel [17] introduced a bulk resistance correction to the TLM technique valid over a wider range of wafer dopant densities and thicknesses compared to that of Berger in order to determine $\rho_{\mathrm{c}}$ on test structures that more accurately reflect the rear contact of silicon solar cells. We have also applied the correction of Eidelloth and Brendel to the data of Figure 2. For high dopant densities a solution to the equations presented in [17] could not be found and so no corrected data is displayed. For the data point at $N_{\mathrm{D}}=5.3 \times 10^{15} \mathrm{~cm}^{-3}$ the corrected value of $\rho_{\mathrm{c}}$ matches the value extracted from the Cox and Strack data of Figure 1, consistent with the Berger correction. More strikingly, at $N_{\mathrm{D}}=1.1 \times 10^{15} \mathrm{~cm}^{-3}$ the correction of [17] reduces the raw data by approximately an order of magnitude to $\rho_{\mathrm{c}} \sim 1 \mathrm{~m} \Omega \mathrm{cm}^{2}$, while at lower dopant densities the correction of [17] has only a marginal effect on the value of $\rho_{\mathrm{c}}$. This may be because the correction of Eidelloth and Brendel does not take into account the 3D effect of lateral spreading resistance, a feature of all of the TLM samples measured in this study.

Indeed, thermionic emission (i.e., current transport over a fixed energy barrier) is independent of surface doping (ignoring effects of image force lowering). The relationship governing the contact resistivity associated with thermionic emission (TE) over a fixed energy barrier is given by the equation [18]:

$$
\rho_{c}(T E)=\frac{k}{q A^{* *} T} e^{q \phi_{B} / k T}
$$

Where $A^{* *}$ is the reduced effective Richardson constant, $k$ is Boltzmann's constant, and $\boldsymbol{\phi}_{\mathrm{B}}$ is the energy barrier at the contact. Inputting the value of the barrier height given by Crowell et al. and using the value of $A^{* *}=110 \mathrm{Acm}^{-2} \mathrm{~K}^{-2}$ from [19] results in a dopant-independent thermionic emission contact resistivity of $\sim 14 \mathrm{~m} \Omega \mathrm{cm}^{2}$, slightly higher than the measured data at $N_{\mathrm{D}}=5.3 \times 10^{15} \mathrm{~cm}^{-3}$, a sufficiently low dopant density for thermionic emission to dominate. Reducing the value of the barrier height to $\boldsymbol{\phi}_{\mathrm{B}}=0.35 \mathrm{eV}$ results in a reduction of the modelled $\rho_{\mathrm{c}}$ (TE) to $\sim 2 \mathrm{~m} \Omega \mathrm{cm}^{2}$. It is likely therefore that the value for the barrier height at the interface of the samples measured here lies somewhere between $0.35-0.4 \mathrm{eV}$, and the contact resistivity values on the lowly doped material actually fall within the values of $\rho_{\mathrm{c}}$ associated with these values for the barrier height. As will be shown in Section 3, results at the solar cell level are consistent with a $\rho_{\mathrm{c}}$ for lowly doped silicon much lower that the values in Figure 2, that is, in better agreement with the thermionic emission model. We conclude, therefore that the error induced by the bulk and lateral spreading resistances compromises the resolution of the TLM extraction, and its correction, especially at low dopant densities. This inaccuracy is likely to contribute to at least some of the apparent doping 
dependence below $N_{\mathrm{D}}=1 \times 10^{17} \mathrm{~cm}^{-3}$ where current transport by thermionic emission dominates. This same artefact would may have also effected the $\rho_{\mathrm{c}}$ results for the $\mathrm{LiF} / \mathrm{Al}$ contact in [10] at low doping densities. Of course, as the wafer or surface dopant density increases beyond $N_{\mathrm{D}}=1 \times 10^{17} \mathrm{~cm}^{-3}$, the contact resistivity becomes dominated by, first thermionic field emission, then field emission processes, and so results in the trend of decreasing $\rho_{\mathrm{c}}$ seen in Figure 2 .

The inset of Figure 2 plots the $I-V$ behaviour of the $\mathrm{Ca} / \mathrm{Al}$ contact on a $2 \Omega \mathrm{cm}$ p-type Cox and Strack structure, demonstrating rectification that is indicative of the formation of a much larger potential barrier for holes at the p-type $\mathrm{Si} / \mathrm{Ca}$ interface, consistent with the generally symmetrical trend of barrier height formation versus metal work function on pcompared to n-type silicon [8]. For reference, the value of $\rho_{\mathrm{c}}$ extracted from the data of Figure 1 is represented in Figure 2 (purple triangle).

\section{PARTIAL REAR CONTACT SOLAR CELLS}

Partial rear contact (PRC) solar cells $\left(\sim 155 \mu \mathrm{m}\right.$ thick; $\sim 2 \times 2 \mathrm{~cm}^{2}$, isolated by a front-side mesa etch) were fabricated on both high $\left(\rho=9.9 \Omega \mathrm{cm} ; N_{\mathrm{D}}=4.5 \times 10^{14} \mathrm{~cm}^{-3}\right)$ and low resistivity $\left(\rho=0.9 \Omega \mathrm{cm} ; N_{\mathrm{D}}=5.4 \times 10^{15} \mathrm{~cm}^{-3}\right) \mathrm{n}$-type float zone silicon wafers. The cells feature a front-side boron diffusion $\left(R_{\text {sheet }} \sim 120 \Omega / \square\right)$ on random pyramid texturing, passivated by an $\mathrm{Al}_{2} \mathrm{O}_{3}$ / $\mathrm{SiN}_{\mathrm{x}}$ stack. The planarised rear-sides of the cells were passivated with PECVD $\mathrm{SiN}_{\mathrm{x}}$. The front contact openings were defined by photolithography and formed by a thermally evaporated $\mathrm{Cr} / \mathrm{Pd} / \mathrm{Ag}$ stack that was later thickened with additional $\mathrm{Ag}$ by electroplating. The rear-side contacts were also defined by photolithography prior to the $\mathrm{Ca} / \mathrm{Al}$ metal evaporation procedure outlined above. Two sets of cells with differing rear contact geometries have been fabricated in this fashion: cells 1 and 3 feature $38 \mu \mathrm{m}$ diameter dots at a pitch of $300 \mu \mathrm{m}$ in a square geometry $\left(f_{\mathrm{c}}=1.26 \%\right)$, while cells 2 and 4 feature the same dot size and pattern at a pitch of $600 \mu \mathrm{m}\left(f_{\mathrm{c}}=0.32 \%\right)$. The pitch and the dot sizes were measured with an optical microscope. Details of the cell architecture are represented in the schematic of Figure 3.

The current-voltage $(J-V)$ characteristics of the cells were measured using both a xenon lamp solar simulator under standard 1-sun conditions $\left(1000 \mathrm{~mW} / \mathrm{cm}^{2}\right.$, AM 1.5 spectrum, $25^{\circ} \mathrm{C}$; Figure 4) and a Sinton Instruments FCT-450 flash tester (Figure 5), both of which were calibrated using a certified reference cell from Franhaufer ISE CalLab. Suns- $V_{\text {oc }}$ measurements were taken using a Sinton WCT 110 (Figure 4) in addition to the flash tester (Figure 5). The quantum efficiency of cell 3 was measured using a Protoflex Corporation QE measurement system (QE-1400-03). Reflection measurements were performed using a PerkinElmer Lambda 1050 UV/VIS/NIR spectrophotometer with an integrating sphere attachment. 
Figure 4 shows the standard one sun light $J-V$ and Suns- $V_{\text {oc }}$ pseudo $J$ - $V$ measurements for the PRC cells fabricated on the 9.9 $\Omega \mathrm{cm}$ wafers. The cells underwent the $\mathrm{Ca} / \mathrm{Al}$ evaporation in the same condition of the Cox and Strack test structures of Figure 1 . The $J-V$ curves show that, impressively, the Ca / Al contact has been successfully implemented on the cells despite the order of magnitude decrease in wafer doping compared to the Cox and Strack test structure. However, it is also apparent that both cells 1 and 2 suffer from large series resistance losses, whose values, calculated from the comparison of the light $J$ $V$ maximum power point (MPP) and the corresponding pseudo $J$-V data point [20] are given in the inset of Figure 4. The high series resistance of the cells is both a result of a high contact resistivity at the $\mathrm{Si} / \mathrm{Ca}$ contact for the lower wafer doping (as per Figure 2) and due to current crowding effects within the cell as the carriers migrate towards the point contacts. These two effects are exacerbated in cell 2 because of its larger pitch and lower contact fraction, resulting in a high series resistance of $4.2 \Omega \mathrm{cm}^{2}$.

While we applied the $\mathrm{Ca} / \mathrm{Al}$ contact structure to a lightly doped wafer to accentuate the effect of the contact resistance, a consequence of using a $9.9 \Omega \mathrm{cm}$ wafer is an increased sensitivity to local recombination, particularly at the $\mathrm{Si} / \mathrm{Ca}$ interface (see Figure 8). The combination of the light base doping and high recombination at the point contacts limits the $V_{\mathrm{oc}}$ of the cells to $612 \mathrm{mV}$ for cell 1 , and $630 \mathrm{mV}$ for cell 2; values that scale appropriately with contact fraction. These simultaneous effects of internal and contact series resistance losses, as well as recombination losses can be, in part, overcome by increasing the phosphorus doping concentration of the base region of the cells.

Figure 5 plots the same one sun light $J-V$ and Suns- $V_{\text {oc }}$ pseudo $J-V$ measurements of the cells fabricated on the $0.9 \Omega \mathrm{cm}$ material. As expected, the efficiency of both cells 3 and 4 increases relative to cells 1 and 2 , from $\eta=15.1 \%$ to $19.7 \%$ for the cells with the $600 \mu \mathrm{m}$ pitch, and from $\eta=17.6 \%$ to $20.3 \%$ for the cells with the $300 \mu \mathrm{m}$ pitch. All cell parameters improved significantly, including the $J_{\mathrm{sc}}$, which increased slightly due to an improvement in the photolithograpic definition of the front metal grid. The integration of the external quantum efficiency (EQE; measured on cell 3) after multiplication by the AM1.5 spectrum yields a short circuit current of $J_{\text {sc } \_ \text {int }} \sim 39.1 \mathrm{~mA} / \mathrm{cm}^{2}$, within tolerable agreement with the light $J-V$ data $\left(J_{\mathrm{sc}}=39.6\right.$ $\mathrm{mA} / \mathrm{cm}^{2}$ ) given the uncertainty in the measurement resulting from, for example, mismatch between illumination areas in the EQE and reflection measurements. We attribute the non-ideal $J_{\mathrm{sc}}$ to a small additional optical loss deriving from the relative reduction in reflection from the $\mathrm{SiN}_{\mathrm{x}} / \mathrm{Ca}$ rear mirror $(R \sim 91 \%$ at $\lambda=1250 \mathrm{~nm})$, compared to $\mathrm{SiNx} / \mathrm{Al}(R \sim 95 \%)$ and $\mathrm{SiNx}$ / $\mathrm{Ag}(R \sim 98 \%)$ rear reflectors. By inputting these reflection values into the generation current model of Basore [21] we calculate an upper limit to the short circuit current of these Ca PRC devices of $J_{\text {sc_max }} \sim 40 \mathrm{~mA} / \mathrm{cm}^{2}$, compared to approximately $40.3 \mathrm{~mA} / \mathrm{cm}^{2}$ and $40.5 \mathrm{~mA} / \mathrm{cm}^{2}$ for $\mathrm{Al}$ and $\mathrm{Ag}$ rear reflectors, respectively. 
To estimate the contribution that the rear $\mathrm{Ca} / \mathrm{Al}$ contact makes to the total recombination, test structures were fabricated to measure the recombination occurring in different areas of the PRC cells. Recombination factors $J_{0}$ for the front boron diffused region and for the rear surface passivated with $\mathrm{SiN}_{\mathrm{x}}$ were extracted from the excess carrier dependent lifetime $\tau_{\mathrm{eff}}(\Delta n)$ of control test structures measured by photoconductance decay (PCD), as reported in [10]. These values, given in Table I, were used in conjunction with the geometrical parameters detailed in Table II to simulate the performance of the various PRC devices, exploring different values of the rear contact surface recombination velocity (SRV). A quasianalytical, iterative model of the three-dimensional device geometry was used to model the output parameters of the solar cell $\left(V_{\mathrm{oc}}, J_{\mathrm{sc}}, F F\right.$ and $\left.\eta\right)$ [22]. A comparison between the measured parameters of the four different solar cells and the simulated results using a lower bound of the rear contact SRV of $S_{\mathrm{c}}=5 \times 10^{4} \mathrm{~cm} / \mathrm{s}$ is given in Table II.

Figure 8 plots the modelled $V_{\mathrm{oc}}$ as a function of $S_{\mathrm{c}}$, with the individual data points representing the measured $V_{\mathrm{oc}}$ values from the light $J$ - $V$ data of Figures 4 and 5. The figure clearly shows that the $V_{\mathrm{oc}}$ is very sensitive to the surface recombination velocity at the contact, particularly for the high resistivity solar cells. From the modelling a lower limit to the contact SRV of $S_{\mathrm{c}}>5 \times 10^{4} \mathrm{~cm} / \mathrm{s}$ can be determined, as indicated by the shaded portion of the plot. This value is one order of magnitude higher than the value determined for $\mathrm{LiF} / \mathrm{Al}$ contacts reported in [10]. It is difficult to be more specific about the value of $S_{\mathrm{c}}$ given the uncertainties in the input parameters for the model, particularly the exact size of the openings in the rear $\mathrm{SiN}_{\mathrm{x}}$ layer, slight variations in which can greatly impact the contact fraction and, as indicated in Figure 8 , the $V_{\text {oc }}$. The modelling results of Figure 8 also indicate that, for the low resistivity cells, $V_{\text {oc }}$ is very weakly dependent on $S_{\mathrm{c}}$ for values above $5 \times 10^{4}$ $\mathrm{cm} / \mathrm{s}$. It is also evident from the modelling that recombination at the rear $\mathrm{Ca} / \mathrm{Al}$ contact remains the main loss mechanism in open-circuit, even for the low resistivity cells.

The small contact fraction of the cells also amplifies the consequences of non-zero rear contact resistivity as demonstrated in Figure 9 which plots the fill factor $(F F)$ versus rear contact resistivity. It can be noted that, for these cell structures, the $F F$ decreases in an approximately linear fashion with the rear contact resistivity $\rho_{\mathrm{c}}$. The dependence is exacerbated when the contact fraction is reduced (from $1.26 \%$ to $0.32 \%$ ), leading to extreme degradation in $F F$ when $\rho_{\mathrm{c}}>10 \mathrm{~m} \Omega \mathrm{cm}^{2}$. The experimental fill factors for the four different cells, also plotted in Figure 9, are in good agreement with the modelled trends. A good fit can be obtained for the low resistivity cells ( 3 and 4) using a contact resistivity of $3.5 \mathrm{~m} \Omega \mathrm{cm}^{2}$, a value that lies between the measured and corrected values of $\rho_{\mathrm{c}}$ for the same wafer resistivity (see Figure 2). For the high resistivity wafers, agreement between the modelling and the cell results of Figure 4 could only be achieved by using a contact resistivity of 7 $\mathrm{m} \Omega \mathrm{cm}^{2}$, an order of magnitude lower than the measured $80 \mathrm{~m} \Omega \mathrm{cm}^{2}$ value of Figure 2 . This is further evidence that the $\rho_{\mathrm{c}}$ 
values in Figure 2 for $N_{\mathrm{D}}<5 \times 10^{15} \mathrm{~cm}^{-3}$ have been largely impacted by bulk resistance contributions, and, as thermionic emission theory would predict, the contact resistivity of the Ca contacts in this study is only weakly dependent on doping concentration.

A reasonable agreement between measured and modelled $R_{\mathrm{S}}$ of the cells is also obtained. In addition to the series resistance associated with the rear contact, the total $R_{\mathrm{s}}$ also includes components due to current crowding towards the partial rear contacts, as well as an additional estimated resistance of $0.3 \Omega \mathrm{cm}^{2}$, representing losses in the front metal grid. Figure 10 shows those resistive contributions to the total $R_{\mathrm{S}}$ for the four cells in this study, as determined by modelling. It can be seen that the contact resistance dominates the series resistance losses for the cells with the small contact fraction (cells 2 and 4 ), and is approximately the largest contributor to the resistive losses in the cells with the largest contact fraction (cells 1 and 3). The data of Figure 10 demonstrates that while the resistance at the rear contacts decreases when reducing the wafer resistivity (commensurate with the decrease in contact resistivity), it is the internal crowding resistance that decreases by the largest proportion of the total $R_{\mathrm{s}}$. This is represented diagrammatically in Figure 9, where the two dashed lines (that is, the $0.9 \Omega \mathrm{cm}$ cells) converge when $\rho_{\mathrm{c}}=0 \Omega \mathrm{cm}^{2}$. Such a convergence does not occur for the high resistivity wafers due to the magnitude of the crowding effects, much greater for the case of $f_{\mathrm{c}}=0.32 \%$ (cell 2) than for $f_{\mathrm{c}}=1.26 \%$ (cell 1 ).

An optimisation of the rear contact fraction is shown in Figure 11, together with the measured conversion efficiencies for the four devices in this study. The modelled results (assuming an identical 3\% metal grid shading for all the cells) indicate that, for the specific set of parameters assumed here, the optimum pitch between the point contacts should be slightly larger (about $400 \mu \mathrm{m} ; f_{\mathrm{c}}=0.71 \%$ ) for the low resistivity wafers than for the high resistivity ones, where the optimum pitch is very close to the $300 \mu \mathrm{m}\left(f_{\mathrm{c}}=1.26 \%\right)$ used to fabricate cell 1. A detailed examination of $V_{\mathrm{oc}}$ and $F F$ as a function of the pitch confirms earlier observations that the optimum in conversion efficiency occurs when the increase of $V_{\mathrm{oc}}$ with increasing pitch is negated by the corresponding drop in $F F$ [22].

The large difference in achievable efficiency between the low and high resistivity wafers is due to the relatively high surface recombination velocity and contact resistivity of the $\mathrm{Ca} / \mathrm{Al}$ contacts implemented here. Such differences would decrease if a low resistance, passivated contact could be developed, possibly via the insertion of an interlayer between the silicon and calcium layer.

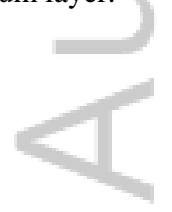




\section{CONCLUSION}

We have demonstrated that Ohmic contact can be formed on n-type silicon over the doping range from $N_{\mathrm{D}}=4.3 \times 10^{13} \mathrm{~cm}^{-3}$ to $1.7 \times 10^{20} \mathrm{~cm}^{-3}$ by direct calcium metallization. The resistivity of the n-type $\mathrm{Si} / \mathrm{Ca} / \mathrm{Al}$ contacts is sufficiently low $\left(\rho_{\mathrm{c}} \sim 2\right.$ $\mathrm{m} \Omega \mathrm{cm}^{2}$ ) that solar cells with partial rear contacts, where the Ca contact fraction comprises $\sim 1 \%$ of the rear surface, can be successfully fabricated without the need for a thermal phosphorus diffusion. The implementation of this PRC cell architecture resulted in a device efficiency of $\eta=17.6 \%$ when applied to a $9.9 \Omega \mathrm{cm}$ wafer. Simply by increasing the dopant density of the base region of the solar cells to $N_{\mathrm{D}}=5.4 \times 10^{15} \mathrm{~cm}^{-3}(\rho=0.9 \Omega \mathrm{cm})$ resulted in a significant reduction in the series resistance losses, as well as the recombination losses suffered at the Ca / Si interface, translating to an increase in device efficiency to $\eta=20.3 \%$. We identify that recombination losses at the $\mathrm{Si} / \mathrm{Ca}$ interface is limiting device performance, losses that could potentially be mitigated with the addition of a passivating interlayer between the silicon and calcium.

\section{ACKNOWLEDGEMENTS:}

This work was performed in part at the Materials node of the Australian National Fabrication Facility, which is a company established under the National Collaborative Research Infrastructure Strategy to provide nano- and microfabrication facilities for Australia's researchers. This work has been supported by the Australian government through the Australian Renewable Energy Agency (ARENA). Work at the University of California, Berkeley was supported by the Bay Area Photovoltaic Consortium (BAPVC). 


\section{REFERENCES}

[1] S. C. Baker-Finch, K. R. McIntosh, D. Yan, K. C. Fong, and T. C. Kho, "Near-infrared free carrier absorption in heavily doped silicon," J. Appl. Phys., vol. 116, no. 6, p. 063106, Aug. 2014.

[2] A. Richter, S. W. Glunz, F. Werner, J. Schmidt, and A. Cuevas, "Improved quantitative description of Auger recombination in crystalline silicon," Phys. Rev. B, vol. 86, no. 16, Oct. 2012.

[3] D. Zielke, C. Niehaves, W. Lövenich, A. Elschner, M. Hörteis, and J. Schmidt, "Organic-silicon Solar Cells Exceeding 20\% Efficiency," Energy Procedia, vol. 77, pp. 331-339, Aug. 2015.

[4] C. Battaglia, X. Yin, M. Zheng, I. D. Sharp, T. Chen, S. McDonnell, A. Azcatl, C. Carraro, B. Ma, R. Maboudian, R. M. Wallace, and A. Javey, "Hole Selective MoOx Contact for Silicon Solar Cells," Nano Lett., vol. 14, no. 2, pp. 967971, Feb. 2014.

[5] J. Geissbühler, J. Werner, S. M. de Nicolas, L. Barraud, A. Hessler-Wyser, M. Despeisse, S. Nicolay, A. Tomasi, B. Niesen, S. D. Wolf, and C. Ballif, "22.5\% efficient silicon heterojunction solar cell with molybdenum oxide hole collector," Appl. Phys. Lett., vol. 107, no. 8, p. 081601, Aug. 2015.

[6] J. Bullock, A. Cuevas, T. Allen, and C. Battaglia, "Molybdenum oxide MoOx: A versatile hole contact for silicon solar cells," Appl. Phys. Lett., vol. 105, no. 23, p. 232109, Dec. 2014.

[7] J. Bullock, C. Samundsett, A. Cuevas, D. Yan, Y. Wan, and T. Allen, "Proof-of-Concept p-Type Silicon Solar Cells With Molybdenum Oxide Local Rear Contacts," IEEE J. Photovolt., vol. 5, no. 6, pp. 1591-1594, Nov. 2015.

[8] D. K. Schroder and D. L. Meier, "Solar cell contact resistance: A review," IEEE Trans. Electron Devices, vol. 31, no. 5, pp. 637-647, May 1984.

[9] J. Bullock, M. Hettick, J. Geissbühler, A. J. Ong, T. Allen, C. M. Sutter-Fella, T. Chen, H. Ota, E. W. Schaler, S. De Wolf, C. Ballif, A. Cuevas, and A. Javey, "Efficient silicon solar cells with dopant-free asymmetric heterocontacts," Nat. Energy, vol. 1, no. 3, p. 15031, Jan. 2016.

[10] J. Bullock, P. Zheng, Q. Jeangros, M. Tosun, M. Hettick, C. M. Sutter-Fella, Y. Wan, T. Allen, D. Yan, D. Macdonald, S. De Wolf, A. Hessler-Wyser, A. Cuevas, and A. Javey, "Lithium Fluoride Based Electron Contacts for High Efficiency n-Type Crystalline Silicon Solar Cells," Adv. Energy Mater., vol. 6, no. 14, May 2016.

[11] H. Hoppe and N. S. Sariciftci, "Organic solar cells: An overview," J. Mater. Res., vol. 19, no. 07, pp. 1924-1945, 2004.

[12] R. H. Cox and H. Strack, "Ohmic contacts for GaAs devices," Solid-State Electron., vol. 10, no. 12, pp. 1213-1218, Dec. 1967.

[13] D. L. Meier and D. K. Schroder, "Contact resistance: Its measurement and relative importance to power loss in a solar cell," IEEE Trans. Electron Devices, vol. 31, no. 5, pp. 647-653, May 1984.

[14] C. R. Crowell, H. B. Shore, and E. E. LaBate, "Surface-State and Interface Effects in Schottky Barriers at n-Type Silicon Surfaces," J. Appl. Phys., vol. 36, no. 12, pp. 3843-3850, Dec. 1965.

[15] H. H. Berger, "Models for contacts to planar devices," Solid-State Electron., vol. 15, no. 2, pp. 145-158, Feb. 1972.

[16] E. G. Woelk, H. Krautle, and H. Beneking, "Measurement of low resistive ohmic contacts on semiconductors," IEEE Trans. Electron Devices, vol. 33, no. 1, pp. 19-22, Jan. 1986.

[17] S. Eidelloth and R. Brendel, "Analytical Theory for Extracting Specific Contact Resistances of Thick Samples From the Transmission Line Method," IEEE Electron Device Lett., vol. 35, no. 1, pp. 9-11, Jan. 2014.

[18] D. K. Schroder, Semiconductor Material and Device Characterization. John Wiley \& Sons, 2006.

[19] S. M. Sze and K. K. Ng, Physics of Semiconductor Devices. John Wiley \& Sons, 2006.

[20] D. Pysch, A. Mette, and S. W. Glunz, "A review and comparison of different methods to determine the series resistance of solar cells,” Sol. Energy Mater. Sol. Cells, vol. 91, no. 18, pp. 1698-1706, Nov. 2007.

[21] P. A. Basore, "Extended spectral analysis of internal quantum efficiency," in , Conference Record of the Twenty Third IEEE Photovoltaic Specialists Conference, 1993, 1993, pp. 147-152.

[22] A. Cuevas, "Electrons and holes in solar cells with partial rear contacts," Prog. Photovolt. Res. Appl., vol. 22, no. 7, pp. 764-774, Jul. 2014. 


\section{TABLES AND FIGURES}

Table I. Parameters utilised in the PRC cell simulations

\begin{tabular}{lll}
\hline Device property & Parameter & Value \\
\hline Doping & Base doping & $4.5 \times 10^{14} \mathrm{~cm}^{-3} \mathrm{or}^{2} .4 \times 10^{15} \mathrm{~cm}^{-3}$ \\
& Boron diffusion sheet resistance & $120 \Omega / \square$ \\
& Wafer thickness & $155 \mu \mathrm{m}$ \\
& Rear dot contact diameter & $38 \mu \mathrm{m}$ \\
& Rear contact pitch & $300 / 600 \mu \mathrm{m}$ \\
Recombination & Surface recombination velocity at rear contact & $5 \times 10^{4} \mathrm{~cm} / \mathrm{s}$ \\
& Passivated rear recombination current & $3 \mathrm{fA} / \mathrm{cm}^{2}$ \\
Optics & Front recombination current & $72 \mathrm{fA} / \mathrm{cm}^{2}$ \\
& Front surface shading & $2-6 \%$ \\
Parasitic resistances & Front antireflection coating on textured surface & $\sim 75 \mathrm{~nm} \mathrm{SiN}$ \\
& Additional series resistance (metal grid) & $0.3 \Omega \mathrm{cm}^{2}$ \\
& Shunt resistance & $>10^{3} \Omega \mathrm{cm}^{2}$ \\
\hline
\end{tabular}

Table II. Comparison between measured and modelled cell performance.

\begin{tabular}{|c|c|c|c|c|c|c|c|c|}
\hline & $\begin{array}{c}\rho_{\text {cell }} \\
(\Omega \mathrm{cm})\end{array}$ & $\begin{array}{c}f_{\mathrm{c}} \\
(\%)\end{array}$ & $\begin{array}{c}\rho_{\mathrm{c}} \\
\left(\mathrm{m} \Omega \mathrm{cm}^{2}\right)\end{array}$ & $\begin{array}{c}J_{\text {sc }}\left(\mathbf{m A} / \mathbf{c m}^{2}\right) \\
\text { measured } \\
\text { (modelled) }\end{array}$ & $\begin{array}{c}\boldsymbol{V}_{\mathbf{o c}}(\mathbf{m V}) \\
\text { measured } \\
\text { (modelled) }\end{array}$ & $\begin{array}{c}\boldsymbol{F F}(\%) \\
\text { measured } \\
\text { (modelled) }\end{array}$ & $\begin{array}{l}\boldsymbol{R}_{\mathbf{s}}\left(\Omega \mathrm{cm}^{2}\right) \\
\text { measured } \\
\text { (modelled) }\end{array}$ & $\begin{array}{c}\boldsymbol{\eta}(\boldsymbol{\%}) \\
\text { measured } \\
\text { (modelled) }\end{array}$ \\
\hline Cell 1 & 9.9 & 1.26 & 7 & 38.9 (38.9) & $612(612)$ & $74(74.1)$ & $1.5(1.3)$ & $17.5(17.6)$ \\
\hline Cell 2 & 9.9 & 0.32 & 7 & $38.8(38.8)$ & $630(652)$ & $61(63.1)$ & $4.2(3.6)$ & $15.1(16.0)$ \\
\hline Cell 3 & 0.9 & 1.26 & 3.5 & $39.6(39.6)$ & $652(654)$ & $78.6(79.9)$ & $0.8(0.6)$ & $20.3(20.7)$ \\
\hline Cell 4 & 0.9 & 0.32 & 3.5 & 39 (39) & $664(673)$ & $75.9(75.3)$ & $1.4(1.6)$ & $19.7(19.8)$ \\
\hline
\end{tabular}




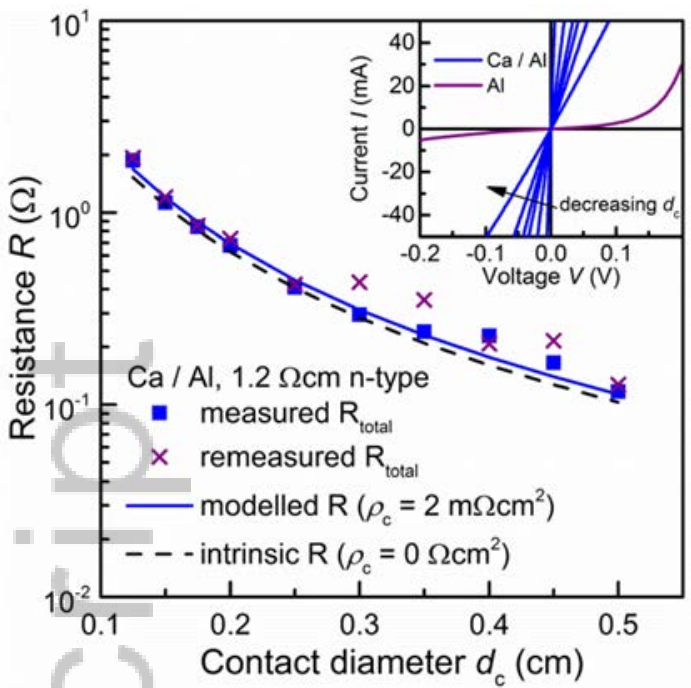

Fig. 1. Contact resistance data used to extract the contact resistivity for the $\mathrm{Ca} / \mathrm{Al}$ structure. Inset: a subset of the $I-V$ curves (blue lines) used to extract the data set in the main figure (blue squares); and typical rectifying contact behaviour of direct aluminium contact measured on the same n-type wafer (purple line)

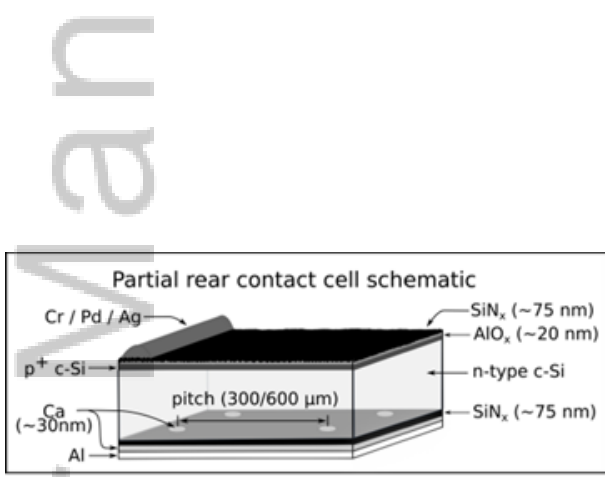

Fig. 3. Schematic diagram of the partial rear contact cell structure. Cells of differing rear contact pitch and resistivity have been fabricated.

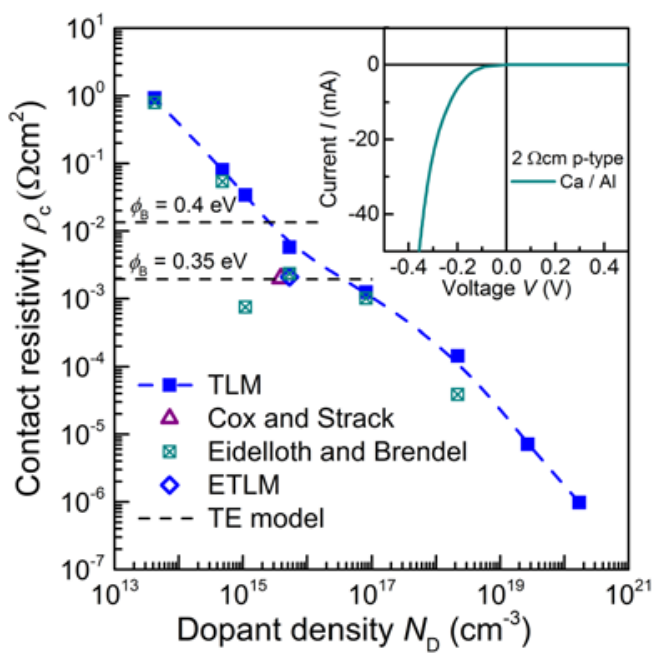

Fig. 2. Contact resistivity as a function of wafer doping concentration extracted by TLM measurements. The purple triangle represents the $\rho_{\mathrm{c}}$ value extracted from the data of Figure 1. Also represented are the TLM data after applying the bulk resistance corrections outlined in [15] and [17], as well as modelled values of thermionic emission $\rho_{\mathrm{c}}$. Inset: the $I-V$ behaviour of the $\mathrm{Ca} / \mathrm{Al}$ contact applied to $2 \Omega \mathrm{cm}$ p-type silicon. 


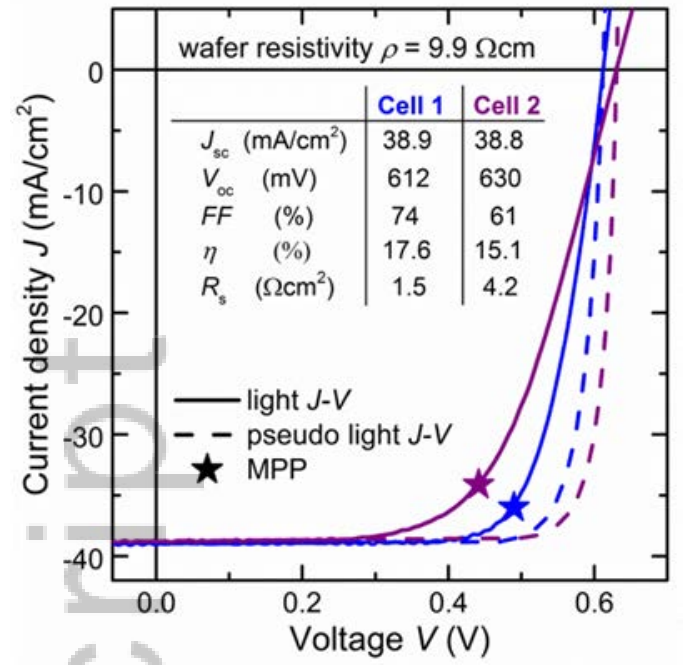

Fig. 4. One sun $J$ - $V$ curves and pseudo $J$ - $V$ curves (from Suns- $V_{\mathrm{oc}}$ ) of the $\mathrm{Ca} / \mathrm{Al}$ PRC solar cells fabricated on lightly doped $\left(N_{\mathrm{D}}=4.5 \times 10^{14} \mathrm{~cm}^{-3}\right)$ n-type wafers. Cell 1 (blue) and cell 2 (purple) differ only in their contact pitch $(300 \mu \mathrm{m}$ vs. $600 \mu \mathrm{m})$ and contact fraction $(\sim 1.26 \%$ vs. $\sim 0.32 \%)$.

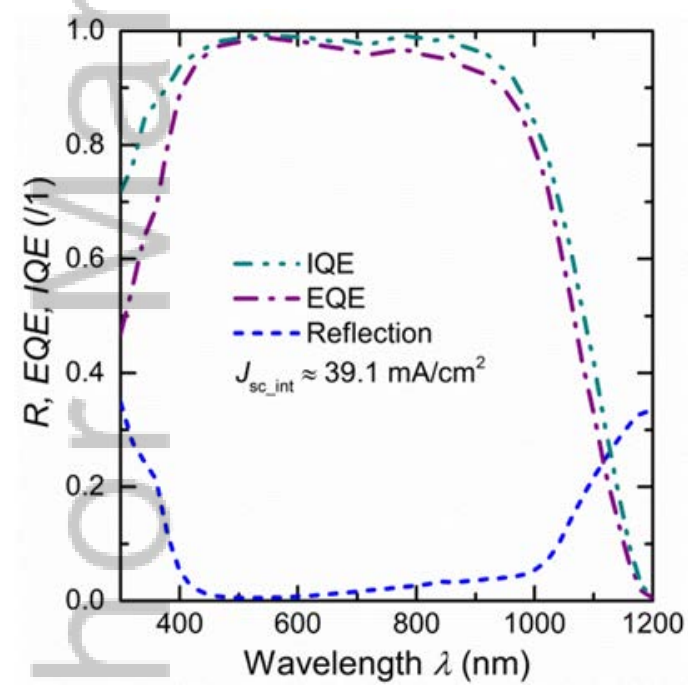

Fig. 6. Quantum efficiency and reflection data of cell 3 .

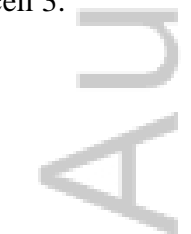

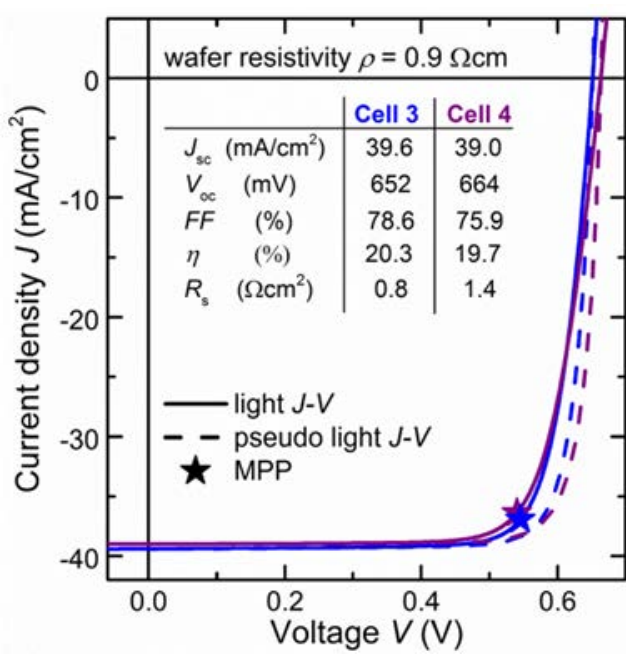

Fig. 5. One sun $J-V$ curves and pseudo $J$ - $V$ curves (from Suns- $V_{\mathrm{oc}}$ ) of the Ca / Al PRC solar cells fabricated on more heavily doped $\left(N_{\mathrm{D}}=5.4 \times 10^{15}\right.$ $\mathrm{cm}^{-3}$ ) n-type wafers. Cell 3 (blue) and cell 4 (purple) are identical in structure to cells 1 and 2 of Figure 3 .

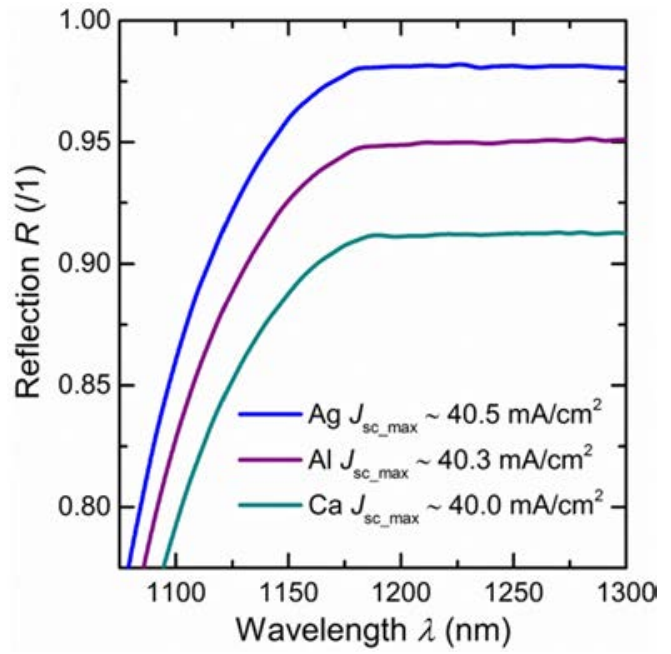

Fig. 7. Rear reflection measurements comparing $\mathrm{Ca} / \mathrm{Al}$ to $\mathrm{Ag}$ and $\mathrm{Al}$ rear mirrors. The structures are planar c-Si with a $75 \mathrm{~nm} \mathrm{SiN}$ layer deposited on both sides of the wafer prior to evaporation of the rear side metal. 


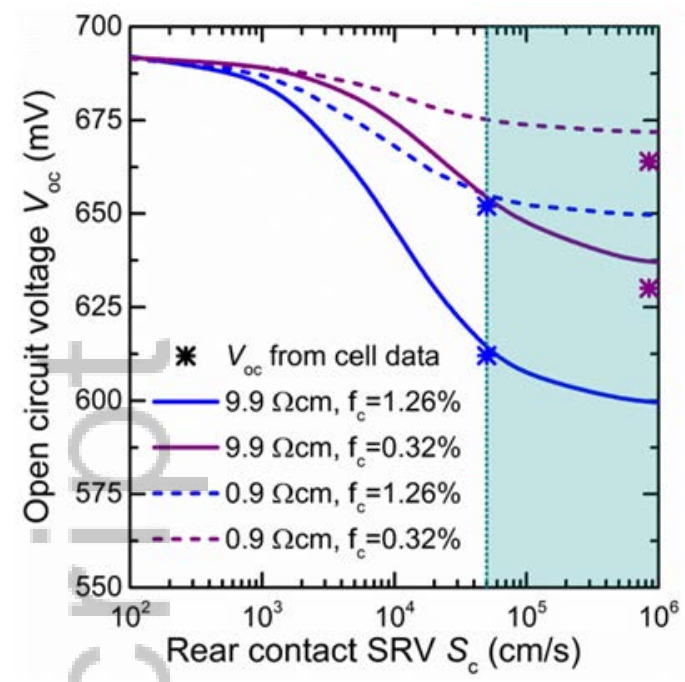

Fig. 8. Results from the modelling of the cell structures fabricated in this study. The shaded region of the graph represents possible values of the SRV at the $\mathrm{Si}$ / Ca contact, given the cells results of Figures 3 and 4.

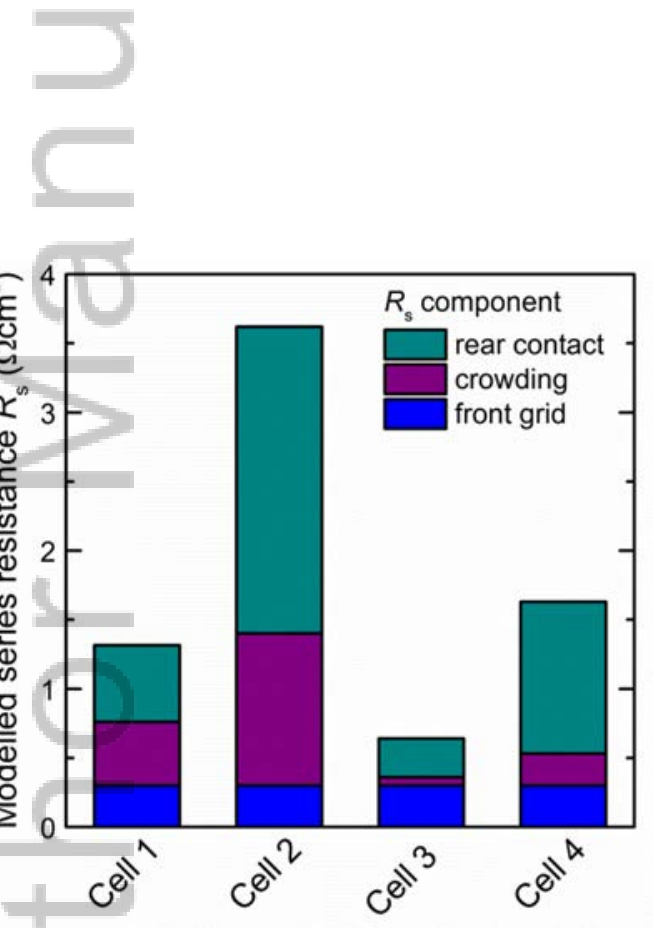

Fig. 10. Breakdown of series resistance components, as determined by modelling. A constant series resistance of $0.3 \Omega \mathrm{cm}^{2}$ from the front metal grid is included in the modelled value.

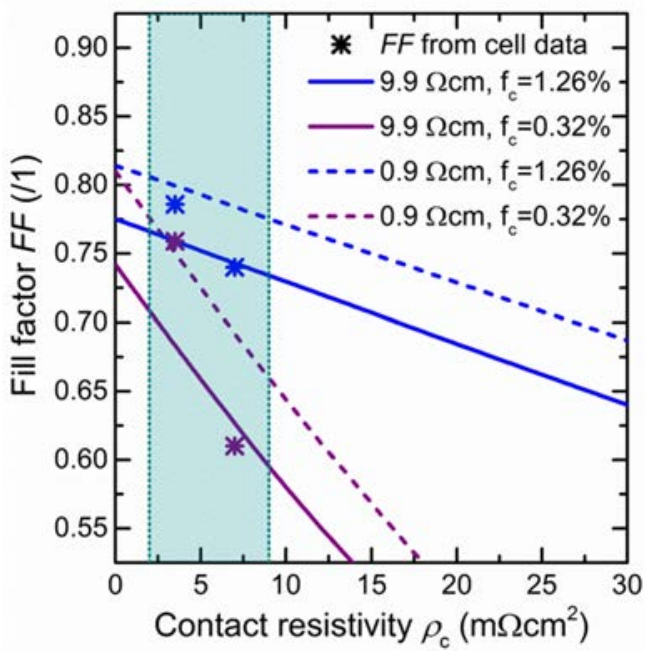

Fig. 9. Modelled values of the fill factor plotted as a function of rear contact resistivity for the cell structures fabricated in this study. The shaded region of the graph represents the possible values of $\rho_{\mathrm{c}}$ given the measured values of the FF for the cells.

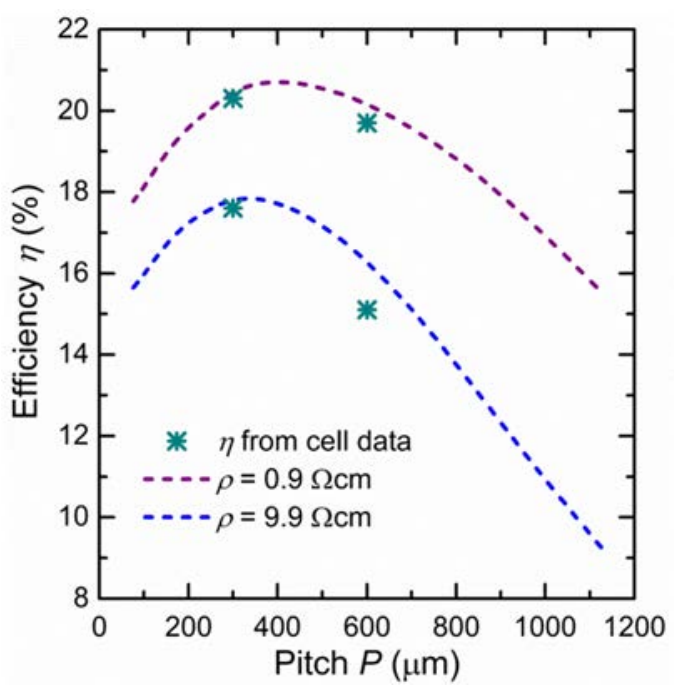

Fig. 11. Optimisation of the contact pitch of the solar cells fabricated in this study. 


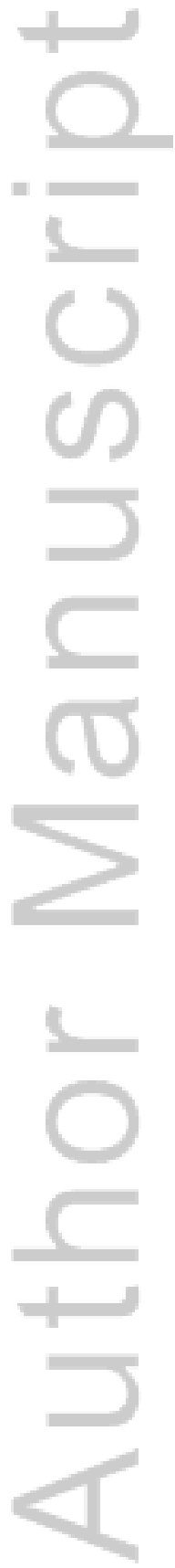

This article is protected by copyright. All rights reserved. 


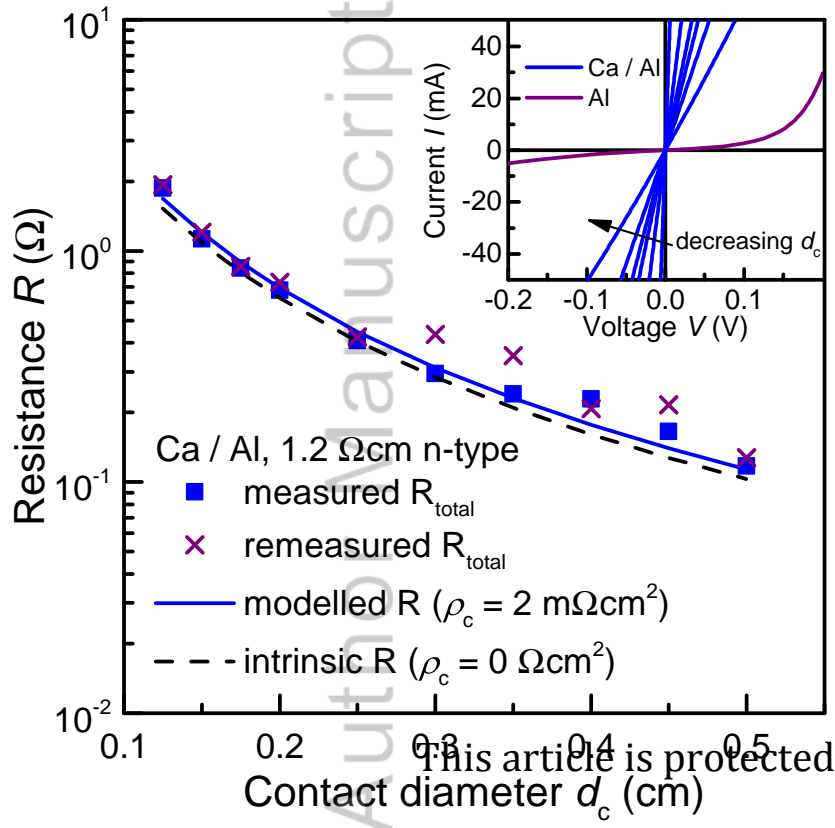




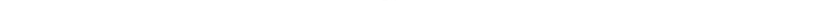




\section{Partial rear contact cell schematic}

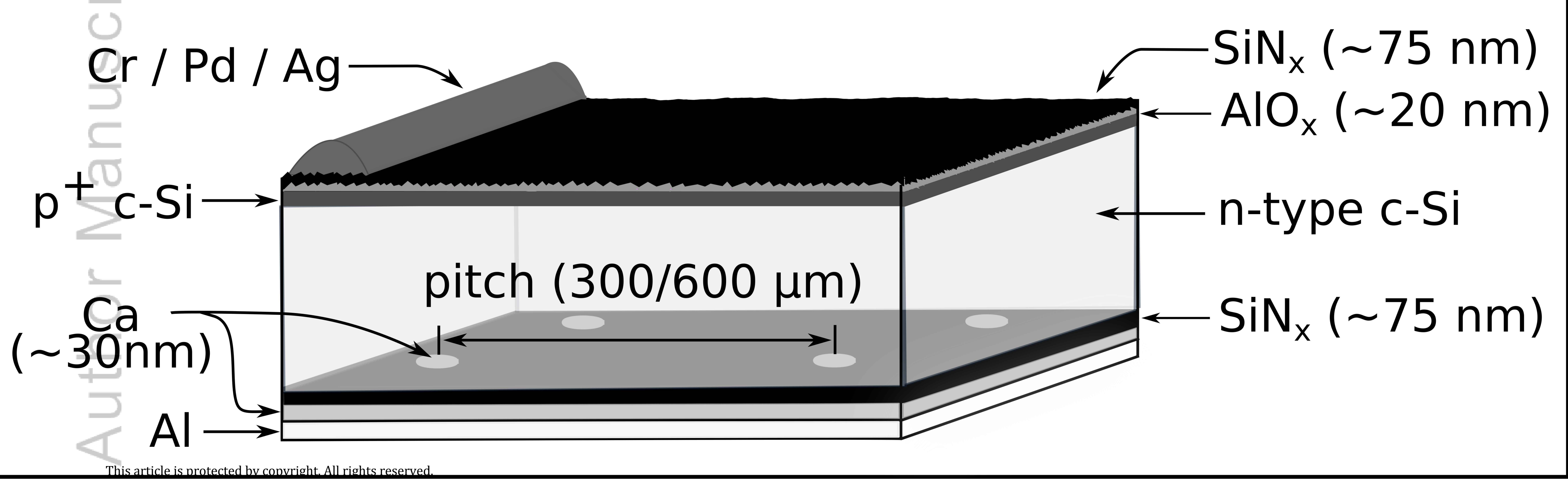




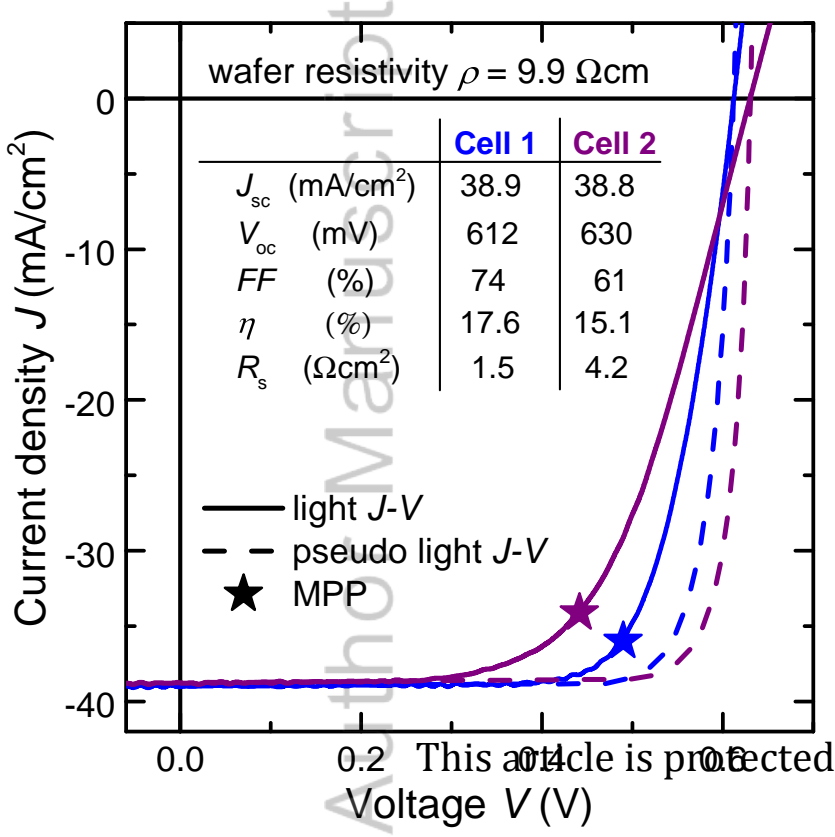




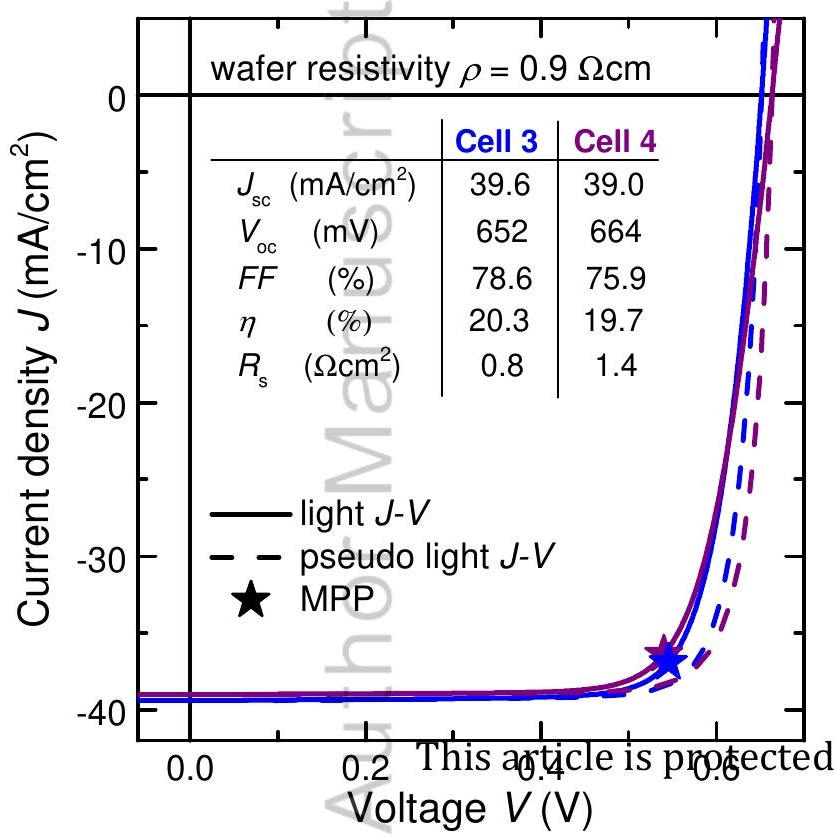




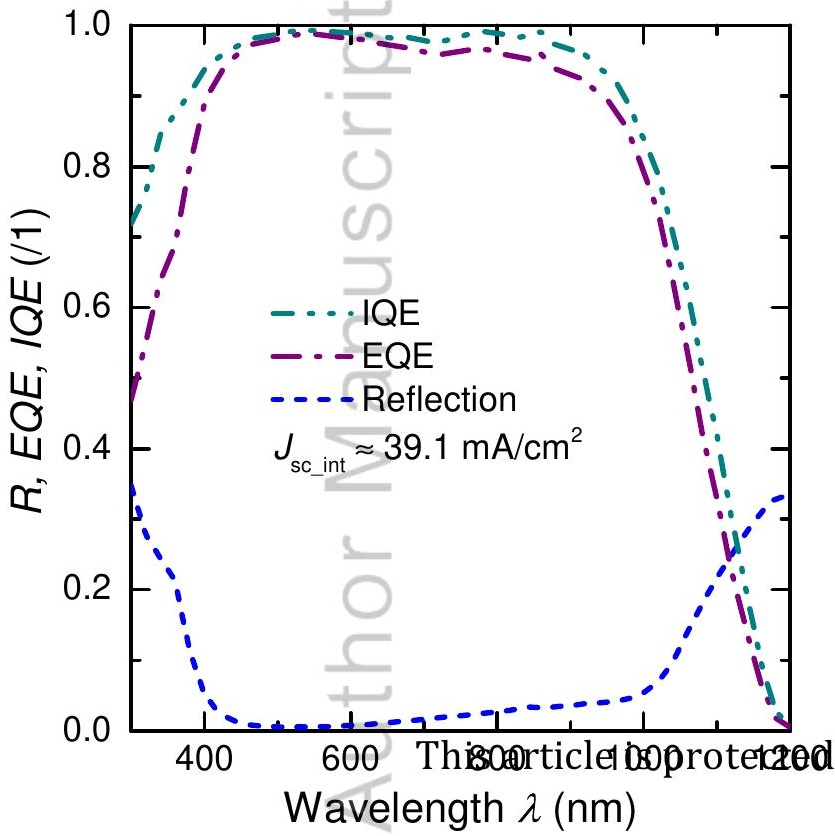




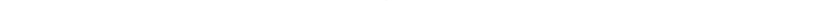




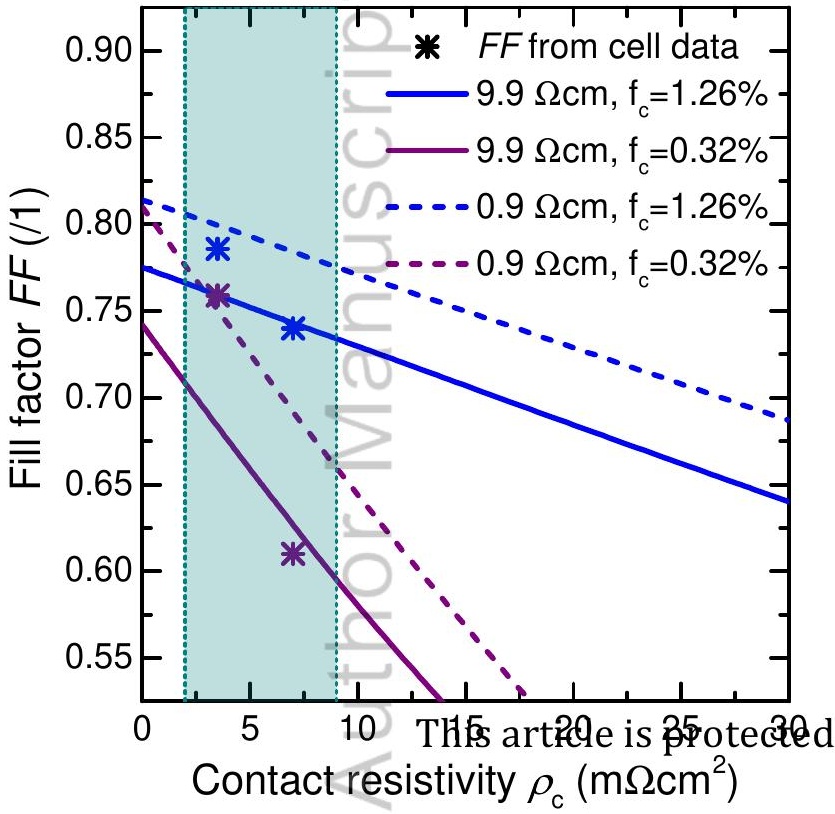




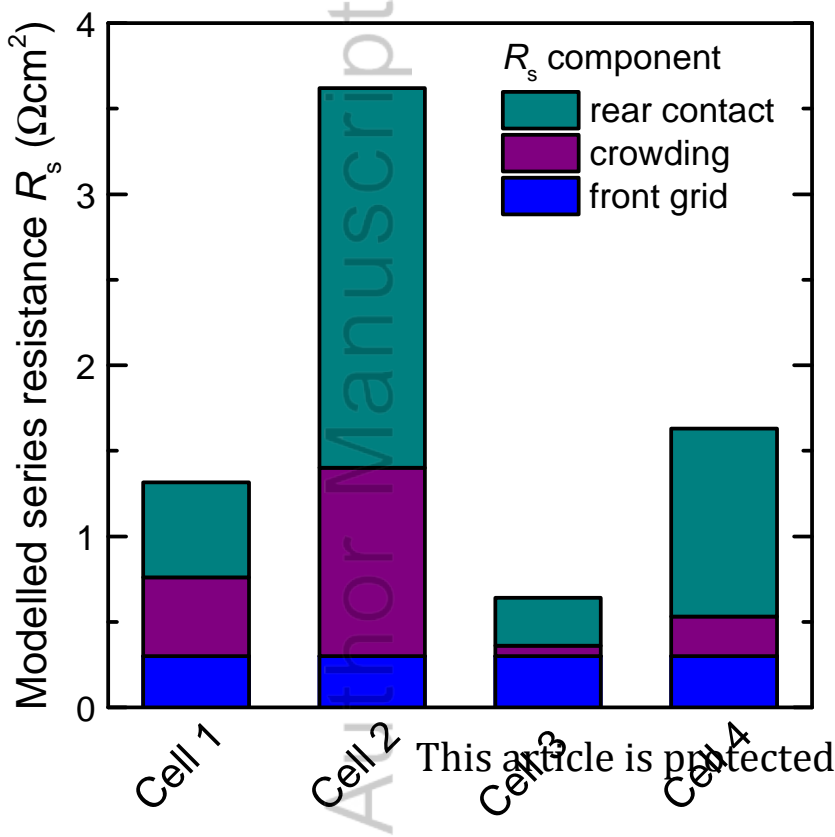




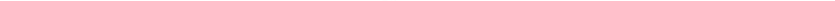




\section{University Library}

\section{- M M N E R VA A gateway to Melbourne's research publications}

Minerva Access is the Institutional Repository of The University of Melbourne

Author/s:

Allen, TG;Bullock, J;Zheng, P;Vaughan, B;Barr, M;Wan, Y;Samundsett, C;Walter, D;Javey, A;Cuevas, A

Title:

Calcium contacts to n-type crystalline silicon solar cells

Date:

2017-07-01

Citation:

Allen, T. G., Bullock, J., Zheng, P., Vaughan, B., Barr, M., Wan, Y., Samundsett, C., Walter, D., Javey, A. \& Cuevas, A. (2017). Calcium contacts to $\mathrm{n}$-type crystalline silicon solar cells. PROGRESS IN PHOTOVOLTAICS, 25 (7), pp.636-644. https://doi.org/10.1002/pip.2838.

Persistent Link:

http://hdl.handle.net/11343/292144 